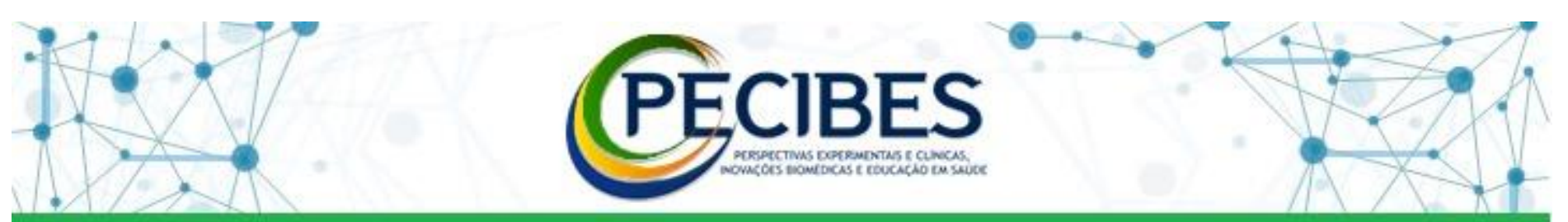

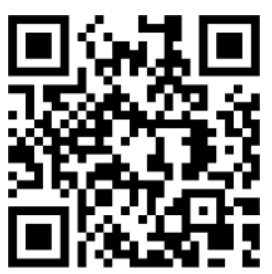

http://www.seer.ufms.br/ind ex.php/pecibes/index

$*$ correspondente:

Tamires Cibeli Biberg e Silva Universidade Federal de Mato Grosso do Sul - UFMS.

E-mail do autor: tamiresbiberg@hotmai 1.com

Descritores:Dor lombar. Prevalência. Treinamento funcional de alta intensidade

Key-words: Low Back Pain. Prevalence. High- Intensity training.

\section{Prevalência de dor lombar entre praticantes brasileiros de treinamento funcional de alta intensidade}

Prevalence of low back pain among Brazilian practitioners of High intensity functional Training

Tamires Cibeli Biberg e Silva ${ }^{1}$, Karina Ayumi Martins Utida ${ }^{1}$, Rafaela Oliveira Cortes ${ }^{1}$, Kallebe Caires de Lima $^{2}$

1. Acadêmicos do curso de Fisioterapia do Centro Universitário Unigran Capital. Campo Grande/Mato Grosso do Sul, Brasil.

2. Fisioterapeuta, doutoranda no Programa de Pós-Graduação em Saúde e Desenvolvimento na Região Centro-Oeste, Faculdade de Medicina/Universidade Federal de Mato Grosso do Sul (UFMS), Brasil.

Introdução: O Treinamento Funcional de Alta Intensidade (TFAI), conhecido como Crosstraining e CrossFit $\AA$, compreende uma modalidade de condicionamento físico extremo. Apesar dos benefícios, críticas são feitas com relação aos exercícios aparentemente aleatórios, e possível falta de individualização dos programas. Sendo a lombalgia uma das principais queixas entre os praticantes. Objetivo: Medir a prevalência de dor lombar pontual, nos últimos 12 meses e em algum momento da vida de praticantes brasileiros de TFAI. Método: Trata-se de um estudo transversal,no qual, foram incluídos 108 participantes de

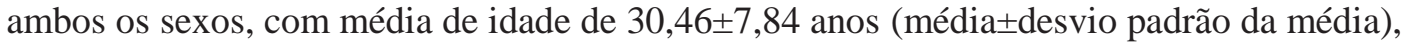
sendo a maioria do sexo feminino $(n=65 ; 60,2 \%)$. Para isso, desenvolveu-se um questionário de pesquisa eletrônica utilizando uma plataforma online (GoogleForms®). Os itens avaliados foram dor lombar em algum momento da vida, nos ultimos 12 meses e dor no momento da entrevista; limitações de atividades por dor lombar e a intensidade da dor, avaliada pela escala numérica de dor O presente estudo foi aprovado pelo Comitê de Ética em Pesquisa (CEP/ UFMS), sob CAAE 42946420.0.0000.0021.. Resultados: O presente resumo apresenta resultados parciaisda pesquisa. Dos 108 participantes incluídos, 91,7\% $(n=99)$ relataram que já sentiram dor lombar em algum momento da vida, enquanto 75,9\% $(\mathrm{n}=82)$ relataram pelo menos um episódio de dor lombar nos últimos 12 meses e 13,9\% $(\mathrm{n}=15)$ relataram estar com dor lombar enquanto respondiam a pesquisa. Dos participantes que relataram estar com dor lombar, 26,7\% $(n=4)$ respoderam que a dor é forte o suficiente para limitar suas atividades habituais e a média de intensidade da dor foi de 5,2 22,11 . Conclusões: Os dados de prevalência de dor lombar entre praticantes de TFAI indicam alta prevalência nos últimos 12 meses e em algum momento da vida, enquanto a prevalência de dor lombar pontual é baixa. 